\title{
The evaluation of the association between the metabolic syndrome and tumor grade and stage of bladder cancer in a Chinese population
}

\author{
This article was published in the following Dove Press journal: \\ OncoTargets and Therapy \\ 7 March 2016 \\ Number of times this article has been viewed
}

Nan Sha',2,*
Hao Xu
Tao Chen
Da-2,*
Wan-qin Xian ${ }^{1,2}$
Lin-Guo Xie
Yu Zhang',2
Chen Xing
Xiao-teng Liu',
Zhong-Hua Shen ${ }^{1,2}$
Zhou-Liang Wu',2
Hai-Long Hu ${ }^{1,2}$
Chang-Li Wu',2
'Department of Urology, The Second
Hospital of Tianjin Medical University,
${ }^{2}$ Tianjin Key Laboratory of Urology,
Tianjin Institute of Urology, Tianjin,
${ }^{3}$ Key Laboratory of Genetics and Birth
Health of Hunan province, Family
Planning Research Institute of Hunan
Province, Changsha, Hunan, People's
Republic of China
*These authors contributed equally
to this work

Correspondence: Hai-Long Hu; Chang-Li Wu

Department of Urology, The Second Hospital of Tianjin Medical University,

Tianjin Institute of Urology, 23 Pingjiang

Road, Hexi District, Tianjin 3002II,

People's Republic of China

Email huhailonglove@I63.com;

wujygc2003@163.com
Objective: The objective of this article was to summarize the relationship between some components of metabolic syndrome (MetS) and the histopathologic findings in bladder cancer in a Chinese population.

Methods: We retrospectively analyzed data of 323 patients from the Department of Urology, Second Hospital of Tianjin Medical University between January 2012 and January 2014. All the patients were diagnosed with bladder cancer for the first time. Age, height, weight, histologic stage, grade, the presence of hypertension, diabetes mellitus, and body mass index were evaluated. The 2009 American Joint Committee on Cancer TNM staging system was used, with Ta and T1 tumors accepted as lower stage and T2, T3, and T4 tumors as higher stage bladder cancers. Also, pathologists assigned tumor grade according to the 1973 World Health Organization grading system. Noninvasive papillary urothelial neoplasms of low malignant potential were regarded as low grade. Analyses were completed using chi-square tests and logistic regression analysis.

Results: Of the 323 patients, 164 had hypertension, 151 had diabetes mellitus, and 213 had a body mass index $\geq 25 \mathrm{~kg} / \mathrm{m}^{2}$. MetS was significantly associated with histologic grade $(P<0.001)$ and stage $(P=0.006)$ of bladder cancer. Adjusted for age in binary logistic regression analysis, the presence of MetS predicts the risk of higher T stage (odds ratio $=4.029, P<0.001$ ) and grade (odds ratio $=3.870, P<0.001$ ) of bladder cancer.

Conclusion: The patients with MetS in the People's Republic of China were found to have statistically significant higher $\mathrm{T}$ stage and grade of bladder cancer.

Keywords: metabolic syndrome, primary carcinoma of the bladder, diabetes mellitus, hypertension, obesity, histologic grade and stage

\section{Introduction}

Bladder cancer is one of the most common malignant neoplasms in the world. ${ }^{1}$ It is the sixth leading cause of new cancer cases and ninth leading cause of cancer-related mortality worldwide. According to the data provided by the International Agency for Research on Cancer in 2012, ${ }^{2} 55,486$ cases and 26,820 deaths were estimated for the population in the People's Republic of China, which accounts for a large proportion of bladder cancer in East Asia (85,451 cases and 37,491 deaths). In developed countries, $\sim 360,000$ men and women are diagnosed with bladder cancer; the highest incidence rates are found in the countries of Europe and North America. ${ }^{3}$ However, it is of note that the incidence of bladder cancer has been steadily increasing in the People's Republic of China over recent years. ${ }^{4}$ 
Several risk factors have been implicated in urinary bladder carcinogenesis, such as chemical industrial products, smoking, and urinary tract infection. ${ }^{5-7}$ Metabolic syndrome (MetS) is characterized by overweight, hypertension, blood glucose, and dyslipidemia. The age-adjusted prevalence of MetS is $9.8 \%$ in males and $17.8 \%$ in females in the People's Republic of China. ${ }^{8}$ It has consistently been associated with an increased risk of cardiovascular diseases and type 2 diabetes, also with a risk of urinary tract diseases. ${ }^{9}$ In recent years, a large number of epidemiological studies have shown that MetS is closely related to the occurrence and development of a variety of malignant tumors. Also, some researches showed that MetS promotes tumorigenesis by a number of inflammatory molecules including interleukin-6 and tumor necrosis factor- $\alpha .^{10,11}$ Association between MetS and prostate cancer, liver cancer, and colorectal cancer has been reported; however, there is a limited large-sample research to evaluate the association between the MetS and risk of bladder cancer in a Chinese population, for separate components and for MetS factors combined. The aim of this study was to investigate the association between components in the MetS (single and combination) with a risk of bladder cancer in a Chinese population.

\section{Patients and methods}

After obtaining approval from the Institutional Review Board of the Second Hospital of Tianjin Medical University, a total of 323 patients at our institution from January 2012 to January 2014 were retrospectively selected for the analysis. Clinical and pathological information were retrospectively obtained from patient charts and electronic medical records, including age, sex, height, weight, body mass index (BMI), blood pressure, fasting serum glucose, tumor grade, and stage. All patients had primary bladder urothelial carcinoma. Patients with metastatic bladder urothelial carcinoma, carcinoma in situ, adenocarcinoma, or squamous cell carcinoma at diagnosis were excluded from this study.

Pathological stage was diagnosed by a single pathologist according to the 2009 tumor-node-metastasis (TNM) classification staging system. Ta and T1 tumors were accepted as lower stage bladder urothelial carcinoma. T2, T3, and T4 tumors were accepted as higher stage bladder urothelial carcinoma. Also, tumor grading was done according to the 2004 World Health Organization grading system. Patients who had noninvasive papillary urothelial neoplasm of low malignant potential were regarded as having low-grade papillary urothelial cancer.

MetS was defined according to the Chinese Diabetes Society definition. ${ }^{12}$ MetS was diagnosed when complying with three or more of the following abnormalities: patients were diagnosed with MetS when they had three or more of the following indications: 1) BMI $\geq 25.0 \mathrm{~kg} / \mathrm{m}^{2}$, 2) fasting plasma glucose $\geq 6.1 \mathrm{mmol} / \mathrm{L}$ or 2 -hour plasma glucose $\geq 7.8 \mathrm{mmol} / \mathrm{L}, 3$ ) systolic blood pressure $\geq 140 \mathrm{mmHg}$ or diastolic blood pressure $\geq 90 \mathrm{mmHg}$, 4) triglyceride (TG) $\geq 1.70 \mathrm{mmol} / \mathrm{L}$ or high-density lipoprotein cholesterol (HDL-C) $<0.9 \mathrm{mmol} / \mathrm{L}$ in males and $<1.0 \mathrm{mmol} / \mathrm{L}$ in females. Participants met the criteria for high blood pressure or high fasting glucose concentration if they underwent hypertension or hyperglycemia treatment. BMI was calculated as weight in kilograms divided by the square of height in meters. Because our database does not include the HDL-C and TG, in order to study, we used a modified Chinese Diabetes Society definition. MetS was diagnosed when complying with the first three conditions of the aforementioned criteria.

Statistical analysis was performed using statistical software (SPSS, version 17.0; SPSS Inc., Chicago, IL, USA). Analyses were completed using chi-square tests and logistic regression analysis. All tests were two-sided with $P<0.05$ considered to be significant.

\section{Results}

As given in Table 1, among the 323 patients analyzed in our study, there were 255 males and 68 females, with an average age of $69.81 \pm 5.821$ years. MetS was found in $64(19.8 \%)$ patients. Some components of MetS such as hypertension, diabetes mellitus (DM), and BMI $\geq 25 \mathrm{~kg} / \mathrm{m}^{2}$ were determined in $50.8 \%, 46.7 \%$, and $65.9 \%$ of patients,

Table I Patients and tumor characteristics

\begin{tabular}{ll}
\hline Clinical characteristics & $\mathbf{N}(\%)$ \\
\hline $\begin{array}{l}\text { No of patients } \\
\text { Sex }\end{array}$ & 323 \\
$\quad$ Male & $255(78.9)$ \\
$\quad$ Female & $68(21.1)$ \\
Age (mean \pm SD) (years) & $69.81 \pm 5.82$ I \\
T stage & \\
$\quad$ Higher stage (T2, T3, and T4) & $56(17.3)$ \\
$\quad$ Lower stage (Ta, TI) & $267(82.7)$ \\
Histologic grade & \\
$\quad$ High grade & $173(53.6)$ \\
Low grade & $150(46.4)$ \\
HBP & $164(50.8)$ \\
DM & $151(46.7)$ \\
BMI (kg/m $\left.{ }^{2}\right)$ & \\
$\geq 25$ & $213(65.9)$ \\
$\quad<25$ & $110(34.1)$ \\
MetS & \\
Yes & $64(19.8)$ \\
No & $259(79.9)$ \\
\hline
\end{tabular}

Abbreviations: SD, standard deviation; HBP, high blood pressure; DM, diabetes mellitus; BMI, body mass index; MetS, metabolic syndrome. 
Table 2 Comparison of pathological characteristics between patients with or without metabolic syndrome

\begin{tabular}{llll}
\hline Variable & MetS & Non-MetS & P-value \\
\hline No of patients & 64 & 259 & \\
$\begin{array}{l}\text { Age (mean } \pm \text { SD) (years) } \\
\text { Sex }\end{array}$ & $65.05 \pm 1.618$ & $70.98 \pm 5.885$ & $<0.00$ I \\
$\quad$ Male & 51 & 204 & 1.000 \\
$\quad$ Female & 13 & 55 & \\
$\begin{array}{l}\text { T stage, } n \text { (\%) } \\
\quad \text { Higher stage }\end{array}$ & $19(29.7)$ & $37(14.3)$ & \\
$\quad$ Lower stage & $45(70.3)$ & $222(85.7)$ & \\
$\quad \begin{array}{l}\text { Histologic grade, } \mathrm{n}(\%) \\
\quad \text { High grade }\end{array}$ & $47(73.4)$ & $126(39.0)$ & \\
$\quad$ Low grade & $17(26.6)$ & $133(61.0)$ & \\
\hline
\end{tabular}

Abbreviations: MetS, metabolic syndrome; SD, standard deviation.

respectively. The clinicopathological demographics of characteristics between patients with or without MetS were demonstrated in Table 2. Sixty-four (19.8\%) patients were diagnosed with MetS. The mean age of the patients in the MetS group was $65.05 \pm 1.618$ years and non-MetS group was $70.98 \pm 5.885$ years. Lower (Ta, T1) and higher (T2, T3, T4) tumor pathologic stages were found in $70.3 \%$ and $29.7 \%$ of patients with MetS, respectively, and histopathologic low grade and high grade were found in $26.6 \%$ and $73.4 \%$ of patients, respectively. According to our data, statistically significant differences were observed in tumor pathologic stage $(P=0.006)$ and tumor histologic grade $(P<0.001)$ between patients with and without MetS. In age-adjusted binary logistic regression analysis, the presence of MetS predicts the risk of higher $\mathrm{T}$ stage (odds ratio $=4.029, P<0.001$ ) and grade (odds ratio $=3.870, P<0.001$ ) of bladder cancer. Also, some MetS parameters (except serum TGs and serum HDL-C) were depicted in Table 3.

\section{Discussion}

In recent years, a large number of epidemiological studies ${ }^{13}$ have shown that MetS is closely associated with the occurrence and development of urinary tract diseases, and the vast majority of research confirmed that MetS was related to the pathogenesis and prognosis of prostate cancer. ${ }^{14}$ However, limited information was available on the association between MetS, as well as the components of MetS, and bladder cancer. So, we explored the association between MetS, as well as the components of MetS, and grading and staging of bladder urothelial carcinoma.

In this study, we retrospectively reviewed 323 patients at our institution, comparing those with MetS with those with non-MetS to assess its potential association with histologic stage and grade of bladder cancer. At the same time, we also assessed the relationship between the three components of the MetS (obesity, DM, hypertension) and bladder cancer histologic grade and stage.

Obesity is one of the characteristics of MetS, according to the population-based longitudinal study in the People's Republic of China; standardized prevalences have reached up to $9.1 \%$ for obese population. ${ }^{15}$ Obviously, it has already accounted for a significant proportion. Therefore, as clinical doctors, we should pay close attention to the disease, especially malignant tumor caused by obesity. A number of studies have shown that obesity is associated with many malignant tumors, and some studies have shown an increased risk. ${ }^{16,17}$ As we know, the relationship between obesity and diabetes, especially type 2 diabetes, is definite. Obesity and DM represent two important components of MetS; epidemiological studies have shown that obesity and type 2 diabetes are associated with an increased risk of several cancers, such

Table 3 Binary logistic regression analyses examining patients with MetS for histopathologic stage and grade of bladder cancer

\begin{tabular}{|c|c|c|c|c|c|c|c|c|}
\hline \multirow[t]{2}{*}{ Variable } & \multicolumn{2}{|l|}{ Stage } & \multirow[t]{2}{*}{ OR $(95 \% \mathrm{CI})^{\mathrm{a}}$} & \multirow[t]{2}{*}{$P$-value } & \multicolumn{2}{|c|}{ Grade } & \multirow[t]{2}{*}{ OR $(95 \% \mathrm{CI})^{\mathrm{a}}$} & \multirow[t]{2}{*}{$P$-value } \\
\hline & Lower & Higher & & & Low & High & & \\
\hline \multicolumn{9}{|l|}{ MetS } \\
\hline Yes & 45 & 19 & $4.029(2.026-8.012)$ & $<0.001$ & 17 & 47 & 3.870 (1.977-7.578) & $<0.001$ \\
\hline No & 222 & 37 & & & 133 & 126 & & \\
\hline \multicolumn{9}{|c|}{$\mathrm{BMI}\left(\mathrm{kg} / \mathrm{m}^{2}\right)$} \\
\hline$\geq 25$ & 169 & 44 & $0.4 I 7(0.209-0.83 I)$ & 0.013 & 84 & 129 & $0.4 \mathrm{I} 0(0.255-0.66 \mathrm{I})$ & $<0.001$ \\
\hline$<25$ & 98 & 12 & & & 66 & 44 & & \\
\hline \multicolumn{9}{|l|}{ DM } \\
\hline Yes & 105 & 46 & $0.114(0.054-0.237)$ & $<0.001$ & 56 & 95 & $0.449(0.284-0.7 \mathrm{II})$ & 0.001 \\
\hline No & 162 & 10 & & & 94 & 78 & & \\
\hline \multicolumn{9}{|l|}{ HBP } \\
\hline Yes & 133 & 31 & $0.702(0.390-1.262)$ & 0.237 & 70 & 94 & $0.698(0.447-1.090)$ & 0.114 \\
\hline No & 134 & 25 & & & 80 & 79 & & \\
\hline
\end{tabular}

Note: ${ }^{a}$ Adjusted for age in logistic regression model.

Abbreviations: MetS, metabolic syndrome; OR, odds ratio; $\mathrm{Cl}$, confidence interval; BMI, body mass index; DM, diabetes mellitus; HBP, high blood pressure. 
as kidney, colon, and liver. ${ }^{18,19}$ The link between obesity and cancer seems to be related to insulin resistance and high serum level of insulin-like growth factor (IGF)-1. ${ }^{20}$ IGF-1 could stimulate proliferation and inhibit apoptosis, which could ultimately result in cancer. Previous reports showed that IGF-1 played an important role in the development of prostate, lung, and liver cancers. Association with bladder cancer has also been presented. ${ }^{21,22} \mathrm{~A}$ BMI $\geq 25 \mathrm{~kg} / \mathrm{m}^{2}$ was used as measurement for obesity in our study. Our results showed that the value of the BMI (obesity) is associated with the pathological grade and stage of bladder cancer in a Chinese population. So far, there are many studies exploring the association between obesity and risk of bladder cancer. Several epidemiological studies have also confirmed that obesity was positively associated with bladder cancer risk. ${ }^{16,17,23}$ Two reasons may be used to explain these results. Biochemically, excess energy in hosts can contribute to risks of carcinogenesis. ${ }^{24}$ Excessive fat is also associated with systemic inflammatory response, which may play an important role in cancer. ${ }^{25}$

Additionally, a number of large cohort studies have made efforts to indicate that there is a higher risk of cancer in populations with DM. Zhan et $\mathrm{al}^{26}$ performed the first study to investigate the characteristics of glucose metabolism in different kinds of cancer in a Chinese population; the results revealed that high level of fasting plasma glucose had a relationship with bladder cancer, and the incidence of hyperglycemia is higher than that of hypoglycemia in the same kind or different kinds of cancer. According to our study, we found that DM was associated with pathological grading and staging of bladder cancer. Possible reasons may be 1) reduced insulin sensitivity and elevated levels of IGF-1, which may in turn stimulate cell proliferation and play an important role in the processes of cancer development and metastasis. ${ }^{27,28}$ 2) In addition, hyperglycemia causes dysfunction of the vital cellular signal system regulated by the protein kinase $\mathrm{C}$ family, which induces the processes of tumor growth and metastasizing in carcinogenesis.

The impact of hypertension and antihypertensive drugs on malignant tumor is still a controversial issue. In the literature, several research evidence has indicated that hypertension in itself represents a significant risk for malignancies, even in a long-term prospective study. ${ }^{29}$ One prospective study demonstrated that systolic blood pressure and risk of cancer mortality were positively correlated only after 5 years of follow-up. ${ }^{30}$ However, little is known about possible pathways between hypertension and cancer. ${ }^{31}$ Dal Moro et $\mathrm{al}^{32}$ performed retrospective analyses of 343 patients, and reported that only hypertension was significantly associated with risk in men among single MetS components. Grove et al, ${ }^{33}$ who conducted a retrospective review of 63 patients, reported no association. There was a nonsignificant correlation between bladder cancer and various kinds of antihypertensive drugs. A study with a total of 1,585 cases conducted in Los Angeles has shown a reduced risk of bladder cancer among hypertensive patients who did not use antihypertensive drugs regularly. ${ }^{34}$ However, there are little data about the association between hypertension and bladder cancer in a Chinese population. Our study showed that there was no correlation between hypertension and histopathologic stage and grade of bladder cancer, but we did not analyze the relationship between antihypertensive treatment and grading, staging, and prognosis of bladder cancer.

According to our data, in the three parameters of MetS, when assessed individually, it has been found a negative or no statistically significant association with histopathologic stage and grade of bladder cancer. However, when they are considered MetSs, patients were found to have statistically significant higher $\mathrm{T}$ stage and grade of bladder cancer.

\section{Limitations}

Our study is not devoid of limitations. First and foremost is its retrospective characteristic and the limited study sample, although all data were extracted from our medical institution, the possibility of selection bias cannot be excluded. In addition, factors that are definitely proved to be associated with bladder cancer risk (such as smoking, urinary tract infection) are not included in the study, which can be related to the MetS. Furthermore, unlike prior studies, our database does not include the HDL-C and TG; it is possible to exclude the patients with MetS actually. Finally, although the BMI can replace central obesity, it cannot accurately explain abdominal obesity, percentage of fat, and body fat distribution.

\section{Conclusion}

Patients with MetS were found to have statistically significant higher $\mathrm{T}$ stage and grade of bladder cancer, while the parameters of MetS, BMI, DM, and high blood pressure, cannot individually predict higher $\mathrm{T}$ stage and grade of bladder cancer. Further researches are needed to confirm our study and to study all urinary tract infections.

\section{Acknowledgments}

This study was funded by the Natural Science Foundation of Tianjin (Nos 12ZCDZSY16600, 14JCYBJC26300, and 
15JCYBJC24600) and the National Key Specialty Construction of Clinical Projects.

\section{Disclosure}

The authors report no conflicts of interest in this work.

\section{References}

1. Jemal A, Bray F, Center MM, Ferlay J, Ward E, Forman D. Global cancer statistics. CA Cancer J Clin. 2011;61(2):69-90.

2. Ferlay J, Soerjomataram I, Dikshit R, et al. Cancer incidence and mortality worldwide: sources, methods and major patterns in GLOBOCAN 2012. Int J Cancer. 2015;136(5):E359-E386.

3. Parkin DM, Bray F, Ferlay J, Pisani P. Global cancer statistics, 2002. CA Cancer J Clin. 2005;55(2):74-108.

4. Yang L, Parkin DM, Li LD, Chen YD, Bray F. Estimation and projection of the national profile of cancer mortality in China: 1991-2005. Br J Cancer. 2004;90(11):2157-2166.

5. Zaridze DG, Karpov RS, Kiseleva SM, et al. [Smoking: the main cause of high mortality rate among Russian population]. Vestn Ross Akad Med Nauk. 2002;9:40-45. Russian.

6. Bosetti C, Pira E, La Vecchia C. Bladder cancer risk in painters: a review of the epidemiological evidence, 1989-2004. Cancer Causes Control. 2005;16(9):997-1008.

7. Kantor AF, Hartge P, Hoover RN, Narayana AS, Sullivan JW, Fraumeni JF Jr. Urinary tract infection and risk of bladder cancer. Am J Epidemiol. 1984;119(4):510-515.

8. Gu D, Reynolds K, Wu X, et al. Prevalence of the metabolic syndrome and overweight among adults in China. Lancet. 2005;365(9468): 1398-1405.

9. Kurella M, Lo JC, Chertow GM. Metabolic syndrome and the risk for chronic kidney disease among nondiabetic adults. $J$ Am Soc Nephrol. 2005;16(7):2134-2140.

10. Gallagher EJ, LeRoith D. Epidemiology and molecular mechanisms tying obesity, diabetes, and the metabolic syndrome with cancer. Diabetes Care. 2013;36(suppl 2):S233-S239.

11. Hammarsten J, Peeker R. Urological aspects of the metabolic syndrome. Nat Rev Urol. 2011;8(9):483-494.

12. Chinese Metabolic Syndrome Study Cooperation. Suggestions about metabolic syndrome of Chinese diabetes society. Chin J Diab. 2004;12 $156-161$

13. Zhang JQ, Geng H, Ma M, Nan XY, Sheng BW. Metabolic syndrome components are associated with increased prostate cancer risk. Med Sci Monit. 2015;21:2387-2396.

14. De Nunzio C, Aronson W, Freedland SJ, Giovannucci E, Parsons JK. The correlation between metabolic syndrome and prostatic diseases. Eur Urol. 2012;61(3):560-570.

15. Hou X, Jia W, Bao Y, et al. Risk factors for overweight and obesity, and changes in body mass index of Chinese adults in Shanghai. BMC Public Health. 2008;8:389.

16. Koebnick C, Michaud D, Moore SC, et al. Body mass index, physical activity, and bladder cancer in a large prospective study. Cancer Epidemiol Biomarkers Prev. 2008;17(5):1214-1221.
17. Holick CN, Giovannucci EL, Stampfer MJ, Michaud DS. Prospective study of body mass index, height, physical activity and incidence of bladder cancer in US men and women. Int $J$ Cancer. 2007;120(1): 140-146.

18. Renehan AG, Tyson M, Egger M, Heller RF, Zwahlen M. Body-mass index and incidence of cancer: a systematic review and meta-analysis of prospective observational studies. Lancet. 2008;371(9612):569-578.

19. Renehan A, Smith U, Kirkman MS. Linking diabetes and cancer: a consensus on complexity. Lancet. 2010;375(9733):2201-2202.

20. Hursting SD, Hursting MJ. Growth signals, inflammation, and vascular perturbations: mechanistic links between obesity, metabolic syndrome, and cancer. Arterioscler Thromb Vasc Biol. 2012;32(8):1766-1770.

21. Yang XQ, Xu C, Sun Y, Han RF. Diabetes mellitus increases the risk of bladder cancer: an updated meta-analysis. Asian Pac J Cancer Prev. 2013;14(4):2583-2589.

22. Qin Q, Xu X, Wang X, Zheng XY. Obesity and risk of bladder cancer: a meta-analysis of cohort studies. Asian Pac J Cancer Prev. 2013;14(5): 3117-3121.

23. Larsson SC, Andersson SO, Johansson JE, Wolk A. Diabetes mellitus, body size and bladder cancer risk in a prospective study of Swedish men. Eur J Cancer. 2008;44(17):2655-2660.

24. Bianchini F, Kaaks R, Vainio H. Overweight, obesity, and cancer risk. Lancet Oncol. 2002;3(9):565-574.

25. Kluth LA, Xylinas E, Crivelli JJ, et al. Obesity is associated with worse outcomes in patients with T1 high grade urothelial carcinoma of the bladder. J Urol. 2013;190(2):480-486.

26. Zhan YS, Feng L, Tang SH, et al. Glucose metabolism disorders in cancer patients in a Chinese population. Med Oncol. 2010;27(2):177-184.

27. Wolf I, Sadetzki S, Catane R, Karasik A, Kaufman B. Diabetes mellitus and breast cancer. Lancet Oncol. 2005;6(2):103-111.

28. Stoeltzing $\mathrm{O}$, Liu W, Reinmuth N, et al. Regulation of hypoxia-inducible factor-1alpha, vascular endothelial growth factor, and angiogenesis by an insulin-like growth factor-I receptor autocrine loop in human pancreatic cancer. Am J Pathol. 2003;163(3):1001-1011.

29. Schmieder RE, Delles C, Messerli FH. Diuretic therapy and the risk for renal cell carcinoma. J Nephrol. 2000;13(5):343-346.

30. Wannamethee G, Shaper AG. Blood pressure and cancer in middle-aged British men. Int J Epidemiol. 1996;25(1):22-31.

31. Stumpe KO. Hypertension and the risk of cancer: is there new evidence? J Hypertens. 2002;20(4):565-567.

32. Dal Moro F, Bovo A, Crestani A, Vettor R, Gardiman MP, Zattoni F. Effect of hypertension on outcomes of high-risk patients after BCGtreated bladder cancer: a single-institution long follow-up cohort study. Medicine (Baltimore). 2015;949:e589.

33. Grove JS, Nomura A, Severson RK, Stemmermann GN. The association of blood pressure with cancer incidence in a prospective study. Am J Epidemiol. 1991;134(9):942-947.

34. Jiang X, Castelao JE, Yuan JM, et al. Hypertension, diuretics and antihypertensives in relation to bladder cancer. Carcinogenesis. 2010;31(11): 1964-1971.

\section{Dovepress}

\section{Publish your work in this journal}

OncoTargets and Therapy is an international, peer-reviewed, open access journal focusing on the pathological basis of all cancers, potential targets for therapy and treatment protocols employed to improve the management of cancer patients. The journal also focuses on the impact of management programs and new therapeutic agents and protocols on

Submit your manuscript here: http://www.dovepress.com/oncotargets-and-therapy-journal patient perspectives such as quality of life, adherence and satisfaction. The manuscript management system is completely online and includes a very quick and fair peer-review system, which is all easy to use. Visit $\mathrm{http}: / / \mathrm{www}$.dovepress.com/testimonials.php to read real quotes from published authors. 